\title{
Consequences of the progression law in the FET phase: a case study
}

\author{
Angela Elisabeth Stott, Hercules Dreyer and \\ Peet Venter
}

\begin{abstract}
The progression law, which restricts grade repetition to once within each of the four phases of basic education, has only been enforced in the Further Education and Training (FET) phase since 2013. The first cohort of progressed learners reached grade 12 in 2014 . We investigate the extent of progression in 2014 in various school quintiles and the observed and speculated future consequences of the progression law in the FET phase. Our mainly quantitative data includes numbers and pass rates for the entire Free State (FS) province, with a focus on the Motheo district. We also draw on some qualitative data in the forms of questionnaires and reports from teachers and mentors working in 22 low quintile schools in Motheo. Our findings show marked differences in extents and impacts of progression between the school quintiles, with low quintile schools acutely impacted and with difficulties likely to escalate in the next few years.
\end{abstract}

\section{Introduction}

Both promotion and progression refer to the movement of a learner to a higher grade. In the case of promotion this is due to the learner having attained the minimum pass requirements stipulated for the grade by the education authority. In the case of progression this is despite not having attained these minimum requirements. The term repetition, in contrast, refers to a learner remaining in a grade instead of moving on with his/her peers. The term retention is sometimes used as a synonym to repetition, but we have chosen DBE (2008)'s use of retention as the antonym of dropout. The terms social and automatic promotion are taken as synonyms in this paper, and refer to the practise of learners of a particular age cohort progressing through school at the same rate as one another, with their progression determined by their age rather than their academic performance (Brophy, 2006). In this paper we use the term social promotion loosely to allow for limited repetition, as is the case in the South African (SA) context. 
In 1998 the SA Department of Education (DoE), now called the Department of Basic Education (DBE), adopted a policy which limited grade repetition to once within a phase (DoE, 1998). We refer to this as the progression law. The progression law legislates social promotion until grade 9 and again from grades 10 to 12 . It is common knowledge that there has been general compliance with the progression law in the General Education and Training (GET) phases for a number of years. However, it seems that the progression law has only been implemented en masse in the FET phase since 2012, in response to a circular issued by the Minister of Basic Education (DBE, 2012).

According to DoE (2007b), learners who achieved certain rather stringent requirements in grade 9 would be awarded a GET certificate and then exit formal schooling or enter the FET phase. The FET phase would be comprised of an academic stream, i.e. grades 10-12, offered by high schools (DBE, 2011; DoE, 2004), and the vocational national curriculum, NC(V), a more practical stream, as offered by TVET (Technical and Vocational Colleges) (DoE, 2007a). Only learners who were promoted (i.e. achieved the stipulated promotion criteria), condoned (according to lesser criteria, given in the policy document), or had achieved qualifications equivalent to the GET certificate, were to be admitted into the FET phase. For the $\mathrm{NC}(\mathrm{V})$ stream, additional provision was made for recognition of prior learning (RPL). It is unclear what the intention was for the remainder of the learners which, in our experience in the low quintile schools in which we work, is the majority.

Despite a massive reconceptualisation of and financial boost to TVET colleges from 2005 to 2009 considerable challenges remain regarding enrolments and throughput rates for these institutions as well as the image employers have about graduates from such institutions (Cosser, Kraak, and Winnaar, 2011). Perhaps because of these, the promised GET school leaving certificate has never been implemented and a large-scale transfer of learners from an academic to a practical stream in the TVET colleges, or into the job market, at the end of grade 9, has not happened (Branson, Hofmeyr, and Lam, 2014), with multiple consequences. These include the problem of what to do with learners who have not passed grade 9 according to the stipulated criteria, and yet who are unwilling or unable to enter an education stream alternative to the FET phase of schooling.

It appears that the response of the DBE, as well as many schools acting independently, has been to disregard the policies' stipulation that a learner may only be enrolled in grade 10 if he/she had met the promotion 
requirements of grade 9. Consequently, progression (Lekalakala, 2013), or upward manipulation of grade 9 marks to mask progression as promotion or condonation (see, for example Padayachee, 2014), of learners from grades 9 to 10 has followed. This has resulted in a large number of learners currently being enrolled in the academic stream of the FET phase without having been promoted to this point through their own academic achievement. Further, since the start of implementation of the progression law in the FET phase, these learners may only fail once within the FET phase, and otherwise must be progressed automatically. The first cohort of progressed learners reached grade 12 in 2014. It seems probable that this contributed to the decrease (of 2,6\%) in pass rate in 2014 compared to 2013 (Motshekga, 2015).

In this article we explore the extent of progression in 2014 and consequences of the progression law, in the FET phase, as we draw on data from all FS schools, with a focus on a subset of 22 low-quintile schools (i.e. schools serving learners from low socioeconomic homes) in the Motheo district, to answer the following questions: (1) What was the extent of progression to grade 12 in schools of various quintiles in the FS in 2014? (2) How has the progression law in the FET phase impacted pass rates and teaching conditions in schools of various quintiles? (3) How can the progression law be expected to impact learner profiles, pass rates and teaching conditions in low quintile schools in the next few years?

\section{Literature review}

The debate about the relative costs and benefits of repetition is hot and polarised. Surveys suggest that most educational practitioners, as well as the general public, frown on social promotion (Alexander, Entwisle, and Dauber, 2003). However, in the academic world, proponents of social promotion coupled with remediation, abound (e.g. Holmes and Matthews, 1984; Jimerson, 2001; Smith and Shepard, 1987). We examine both sides of the argument and the contexts in which they are made relative to the SA context, as a framework for interpreting the findings of this study. 


\section{The social promotion debate}

Proponents of social promotion cite studies which show that repetition has social and academic costs and few if any long-term benefits. Holmes and Matthews (1984) conclude their meta-analysis of the repetition of elementary and junior high students by stating that: "Those who continue to retain pupils at grade level do so in spite of cumulative research evidence showing the potential for negative effects consistently outweighs positive outcomes" (p.17). These negative effects include an increased likelihood of dropping out of school before graduation (Jimerson, 2001) and behavioural problems, including truancy (Jimerson, Carlson, Rotert, Egeland, and Sroufe, 1997). The economic costs of repetition are also high (Alexander et al., 2003). These include not only the costs of having additional learners in the system, but also the lower earning-potential such learners will have once they drop out of, rather than graduate from, school. Smith and Shepard (1987) state that repetition and ability grouping "[help] advantaged groups, [create] further barriers for the disadvantaged, and [promote] segregation and stratification" (p.133). This is possibly worsened by the somewhat arbitrary nature of promotion, progression and repetition decisions, particularly in developing countries (Brophy, 2006). Proponents of social promotion admit that learners may show an initial improvement in academic performance relative to matched controls on the short term, but point out that this benefit disappears in the long term (Manacorda, 2012).

Opponents of social promotion may argue that promotion on merit, as defined by school curricula, serves all children's interests by channelling learners into areas most suitable for their ability. Alexander et al. (2003) refute this argument by stating that ability is not static and school assessment not infallible, and so potential to succeed cannot necessarily be determined by performance in school assessments at a particular time. Teachers are the main opponents to social promotion. Their concerns are sometimes belittled by researchers as being only informed by practical knowledge of the short-term benefits of repetition, rather than by rigorous research of both short- and longterm effects of repetition (Brophy, 2006; Haidary, 2013). The problems teachers associate with progression are well summarised in this frequently quoted statement by the American Federation of Teachers (1997, p.5):

Social promotion is an insidious practice that hides school failure and creates problems for everybody - for kids, who are deluded into thinking they have learned the skills to be successful or get the message that achievement doesn't count; for teachers who must face 
students who know that teachers wield no credible authority to demand hard work; for the business community and colleges that must spend millions of dollars on remediation; and for society that must deal with a growing proportion of uneducated citizens, unprepared to contribute productively to the economic and civic life of the nation.

One of the concerns mentioned above is that if learners know that they will be automatically progressed they will not be motivated to work hard due to the loss of the threat effect of grade repetition. Proponents of social promotion deny the efficacy of the threat effect of grade repetition in improving learner performance since they consider the assumptions that it is based upon to be faulty. These assumptions are that learners who fail are underachievers who do not apply themselves, rather than low achievers who already work hard, and that the threat of failure is motivating, rather than demotivating (Brophy, 2006). Belot and Vandenberghe (2014) found empirical support for this renouncement of the threat effect of repetition amongst French-speaking Belgian grade 10 learners. These learners showed no difference in performance for those who knew they would be socially progressed, relative to those who had the possibility of failing their grade.

\section{The South African context}

Whether such findings are generalisable to SA learners is not known. Most of the available studies on repetition have been conducted in developed countries (Brophy, 2006) and so their findings may not be applicable to the SA context. For example, the social and psychological consequences of repetition are likely to be reduced in situations where a large portion of a class repeats the grade relative to where the repeating learner is more likely to be isolated and marginalised due to the majority of his/her peers having been promoted. Additionally, the likelihood of a learner dropping out of school because of having repeated a grade some time in their schooling history is reduced in contexts of poverty if the school offers shelter and food which would otherwise not be available. Factors such as these clearly contribute to the fact that black schools in South Africa exhibit high enrolment and retention rates despite having high repetition rates (Branson et al., 2014; Lam, Ardington, and Leibbrandt, 2011).

Countries which practise social promotion include those listed by the SA Minister of Basic Education, Angie Motshekga, in her speech regarding the 2014 matric results (Motshekga, 2015). These (Finland, Sweden, Denmark, Japan, Korea and the United Kingdom) are all developed countries who have 
strong remediation systems in place and who perform very well in international comparative tests. They exhibit very different classroom conditions to those experienced in typical low quintile SA schools. Motshekga admitted that SA's education system lacks the necessary remediation required for social promotion to be successful when she pointed out that "we need to strengthen our support programme for [progressed] learners" (Motshekga, 2015, p.4). It is well established that in typical low quintile SA schools the undue emphasis on grade 12 has the effect of reducing the occurrence of remediation in lower grades and is detrimental to normal school functioning. See, for example Clark and Linder (2006). The United States, which does experience pockets of problems similar to low quintile SA schools, has experienced a popular move away from social promotion in recent years (National Science Teachers Association, 2003), but still exhibits low rates of repetition in general, although repetition rates of minority groups in certain areas are high (Brophy, 2006).

Brophy (2006) lists grade repetition rates for various countries and regions throughout the world, with 22\% per year, recorded for sub-Saharan African countries, being the highest. However, Branson et al. (2014), report that as many as $80 \%$ of 2008 grade 10 learners in the lowest quintile schools in South Africa had not reached grade 12 by 2010. Their data show dramatic increases in repetition and drop-out rates between grades 10 and 11 and grades 11 and 12. This is unsurprising since the progression law was not yet being implemented in these grades at the time their data were collected. It is known that not all of this repetition was legitimate, but was rather part of a practise referred to as gatekeeping (DBE, 2012). Gatekeeping in this context means preventing learners from being promoted to grade 12 despite having met the promotion requirements, albeit poorly, if they are likely to fail the final examination, and so lower the pass rates of the school in the national grade 12 examination. It is understandable that gatekeeping was a common practise (Chisholm and Wildeman, 2013) before implementation of the progression law in the FET phase since there is considerable emotional, financial and political pressure to ensure that pass rates are competitive. In situations where educational pathways alternative to grade 12 are not present, gatekeeping, as well as repeated failure to meet the promotion requirements, can result in learners dropping out from the education system with low skills and therefore low levels of employability. 


\section{Methodology}

\section{Sample and data collection}

To answer the first research question we used quantitative data from all the 2014 grade 12 candidates in the FS province. These data were obtained from the DBE, and are used with permission. Quantitative and qualitative data were collected from 22 low quintile schools within the Motheo district to answer the second research question. We refer to these schools as the project schools. Qualitative data comprised open-ended questionnaires and daily and quarterly reports. The reports, dating from January 2014 to May 2015, were provided by 15 highly experienced and qualified master teachers who work as mentors, visiting classes and supporting teachers, in these schools most days of the school term. The questionnaires were administered in June 2014 to all mathematics, physical sciences and accounting teachers at these schools, although only 33 responses out of 95 (35\%) were returned to us. Additionally, the quantitative data used for the first research question informed the answer to the second research question. To answer the third research question we collected quantitative data about enrolment and progression numbers in the FET phase from the project schools. We also used quantitative data about numbers of overage learners per grade, for the entire Motheo district. This data were also obtained from the DBE and used with permission.

\section{Data analysis}

Quantitative data analysis involved simple statistical procedures as guided by each research question. For example, in answer to the first and second research questions, data analysis involved calculating and graphing numbers and percentages of learners who had been progressed, compared to promoted, to grade 12 in 2014, and the grade 12 final examination pass rates for each school quintile. Qualitative analysis involved forming coding categories which were grounded in the questionnaire and mentor report data, followed by coding and summarising the relevant entries according to these categories. 


\section{Results}

\section{Extent of learner progression}

Of the 26439 grade 12 candidates in the FS in 2014, $3919(14,8 \%)$ had been progressed to grade 12 from grade 11 at the end of 2013. We refer to these learners as progressed learners. Figure 1 shows that of the 79 Motheo schools who had grade 12 candidates in 2014, 28 had no progressed learners while for 17 schools more than $30 \%$ of their candidates were progressed, to as much as $58,5 \%$.

As shown in Table 1, higher quintile (wealthier) schools have a significantly lower occurrence of progression. There are only 17 quintile 5 schools in the Motheo district and 64 of the 109 progressed learners in these schools were within only two of these schools. If these two schools are disregarded, the fraction of progressed learners in quintile 5 schools in Motheo drops to a mere $2 \%$, in stark contrast to $27,7 \%$ in quintile 1 and 2 schools.

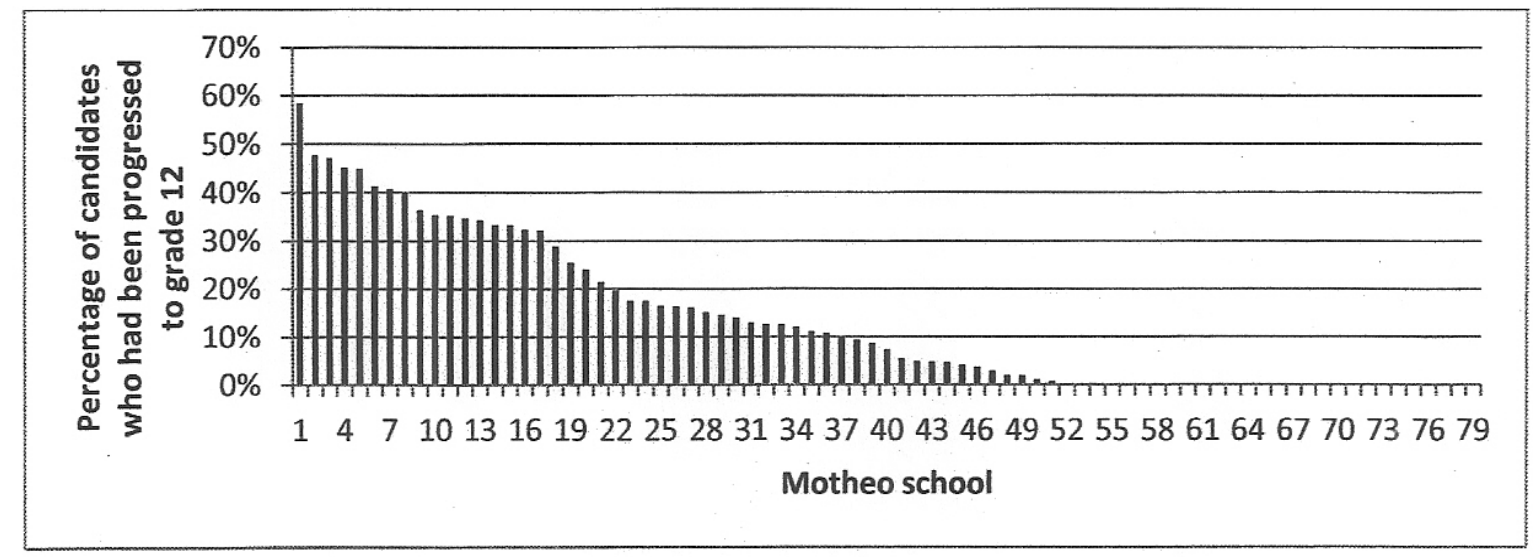

Figure 1: Extent of learner progression to grade 12 in 2014 in the Motheo district per school 
Table 1: Number and percentage of progressed learners in Motheo district per quintile

\begin{tabular}{|c|c|c|c|}
\hline Quintile & No. of learners & $\begin{array}{c}\text { No. of progressed } \\
\text { learners }\end{array}$ & $\begin{array}{c}\text { \% progressed } \\
\text { learners }\end{array}$ \\
\hline $1 \& 2$ & 2967 & 822 & 27.7 \\
\hline 3 & 1963 & 347 & 17.7 \\
\hline 4 & 1033 & 80 & 7.7 \\
\hline 5 & 2605 & 109 & 4.2 \\
\hline
\end{tabular}

\section{Effects of learner progression}

As shown in Figure 2, the FS promoted learners' pass rate was relatively high, at $88,7 \%(\mathrm{n}=22520)$, with little variation between the districts. However, since only 49\% (1 934 out of 3919 ) of the progressed learners passed, the overall $(n=26439)$ pass rate was depressed by 5,9 percentage points to only $82,8 \%$. This is 4,6 percentage points lower than the $87,4 \%$ the FS achieved in

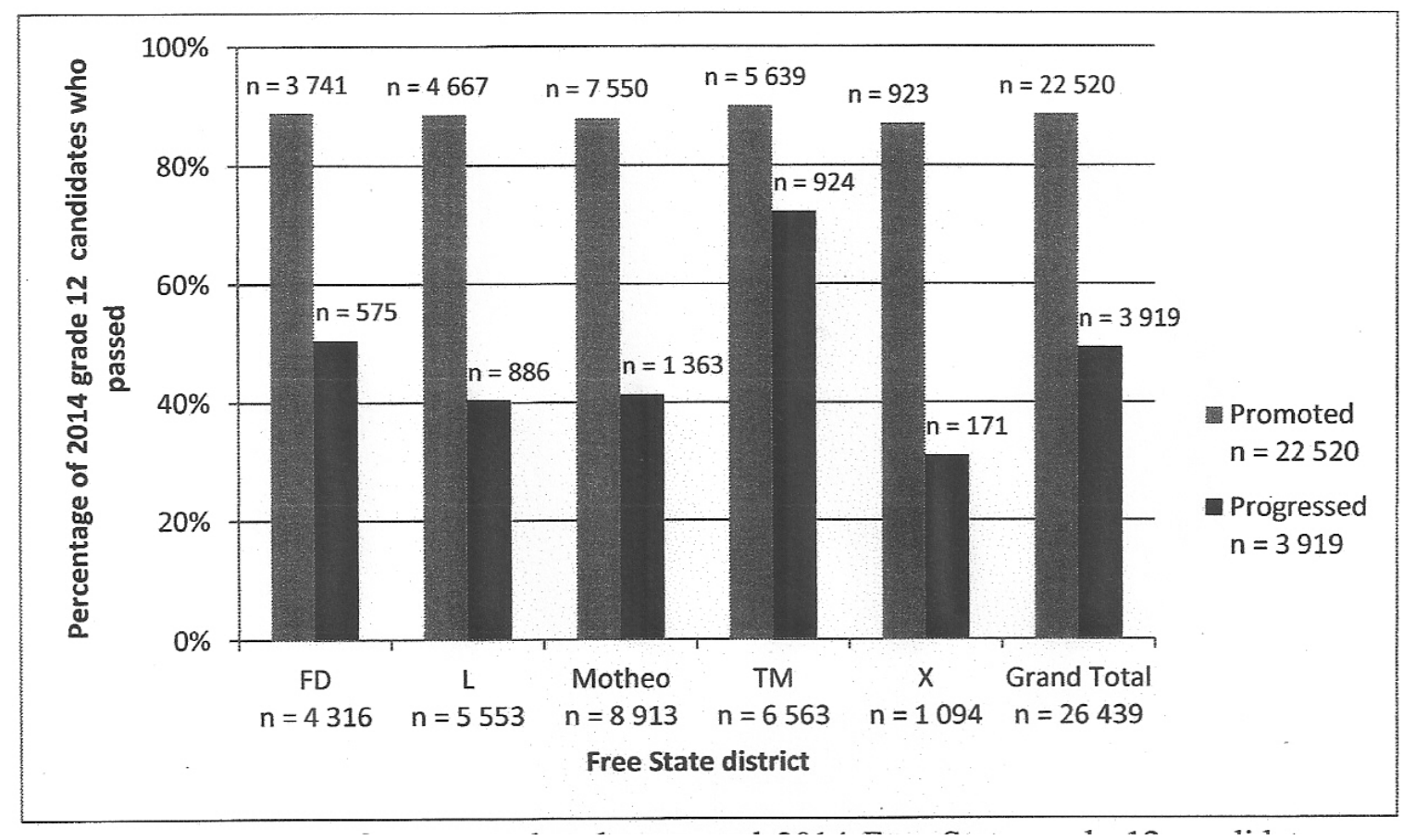

Figure 2: Pass rates of progressed and promoted 2014 Free State grade 12 candidates, per district, according to whether progressed or promoted

2013. The progressed learners' pass rates vary noticeably between the districts from 31\% (53 out of 171) for Xhariep to $72 \%$ (668 out of 924 ) for 
Thabo Mofutsanyana. Of the 51 Motheo schools which had progressed learners, 27 had pass rates below $30 \%$ for their progressed learners. As shown in Table 2, the pass rate depression caused by the progressed learners was significantly lower for schools of higher quintile.

Table 2: Pass rate in the Motheo schools according to quintile

\begin{tabular}{|c|c|c|c|c|}
\hline Quintile & $\begin{array}{c}\text { Pass rate of } \\
\text { promoted } \\
\text { learners }\end{array}$ & $\begin{array}{c}\text { Pass rate of } \\
\text { progressed } \\
\text { learners }\end{array}$ & $\begin{array}{c}\text { Pass rate } \\
\text { of all } \\
\text { learners }\end{array}$ & $\begin{array}{c}\text { Effect of } \\
\text { progressed } \\
\text { learners }\end{array}$ \\
\hline $1 \& 2$ & 82.4 & 31.4 & 68.0 & -14.4 \\
\hline 3 & 85.6 & 51.3 & 79.5 & -6.1 \\
\hline 4 & 89.3 & 58.8 & 86.9 & -2.4 \\
\hline 5 & 94.4 & 73.4 & 93.5 & -0.9 \\
\hline
\end{tabular}

Two of the 33 teachers who completed the questionnaire (out of 95 teachers to whom the questionnaires were given) were from a school which was not yet complying with the progression law. The remainder all expounded on the difficulties they experienced due to progression. The recurring themes in their open-ended responses include that the progressed learners are slow, making it difficult for the teacher to keep up with the pace setter, unmotivated, disinterested, ill-equipped, ill-disciplined, unable to cope, often truant from class and extra classes and do not do their class- and home-work. These claims were verified by all of the mentors who identified additional themes which include: Shortages of resources such as desks, chairs and text books due to increased class sizes; Burn-out among teachers due to having to give extra classes in the afternoons and weekends; Demoralisation among the teachers due to the poor performance of the progressed learners and pressure from the DBE to get these learners to perform better; Reports of teachers resigning (9 teachers), threatening to resign (3) or refusing to teach classes containing progressed learners (2) as a result of the difficulties caused by the progression law. An example from these reports, referring to an exemplary grade 12 mathematics teacher, is given below:

She is demotivated due to the meeting she had with the committee from the department yesterday. They wanted an explanation why four of her matrics failed last year. They have failed since grade 10 and were promoted to grade 12 .

Another recurrent theme in the mentors' reports was the focus on grade 12 at the expense of lower grades, particularly in the third quarter, when a number 
of camps and extra lessons were arranged for grade 12 learners. These took grade 12 teachers out of their other classes. Examples include: "The grade $12 \mathrm{~s}$ started with marathon sessions again this week. The grade 12 educators must leave their other classes again and concentrate on the grade 12s"; "Educator couldn't teach grade 10 and 11 last week, he had to teach grade 12s. Grade $11 \mathrm{~s}$ are about three weeks behind schedule." "The grade 8 and 9 learners are left on their own, the teachers use the periods for teaching grade 11 and 12."

Projected effects of learner progression

Figure 3 shows the numbers of learners and percentages of over-aged learners per grade for the FS for 2015. There is a sharp increase in both numbers and percentage of overaged learners from grade 9 to grade 10 . Over $20 \%$ of learners in each grade of the FET phase are overage (more than two years older than grade age). Each of the ten low quintile project schools shown in Table 3 has considerably higher fractions of progressed learners in 2015 than in 2014 , with a total increase of 18 percentage points. One school has an increase of over $150 \%$, from $34,7 \%$ to $88,8 \%$.

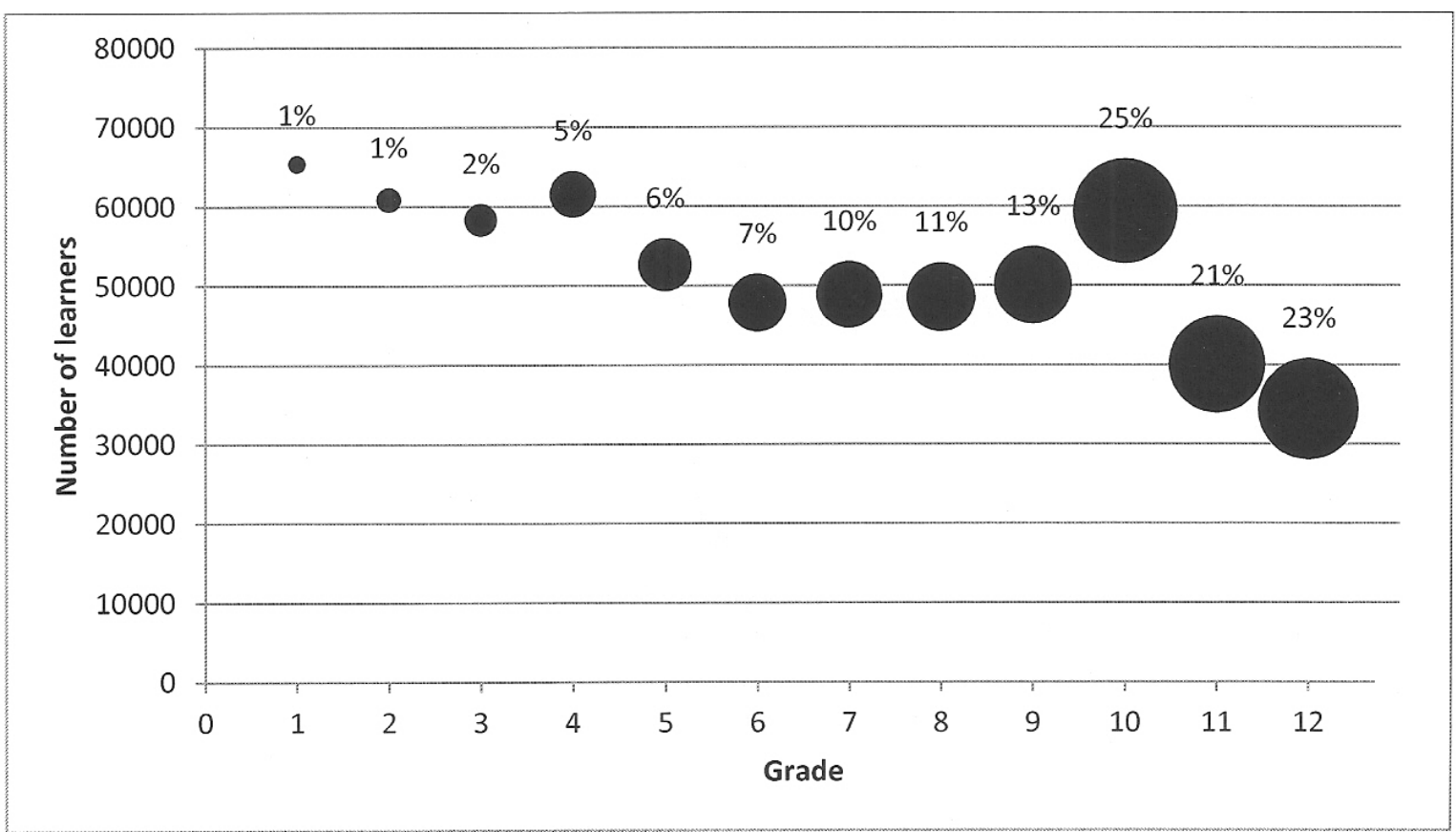

Figure 3: Numbers of learners, per grade, for Free State schools, 2015. Bubble sizes and values show percentages of overage learners in each grade 
Table 3: Numbers and percentages of learners promoted / progressed to grade 12 in 2015 , compared to 2014 , for ten low quintile schools in the Motheo district

\begin{tabular}{|c|c|c|c|c|}
\hline \multicolumn{5}{|c|}{ Botshabelo } \\
\hline School & $\begin{array}{c}\text { Progressed } \\
2014\end{array}$ & $\begin{array}{c}\text { Progressed } \\
2015\end{array}$ & $\begin{array}{c}\text { \% Progressed } \\
2014\end{array}$ & $\begin{array}{c}\text { \% Progressed } \\
2015\end{array}$ \\
\hline B1 & 70 & 259 & 47.7 & 71.7 \\
\hline B2 & 15 & 34 & 17.6 & 27.4 \\
\hline B3 & 53 & 242 & 33.3 & 64.5 \\
\hline B4 & 107 & 98 & 58.5 & 48.0 \\
\hline B5 & 70 & 171 & 35.4 & 53.3 \\
\hline $\begin{array}{l}\text { Botshabelo project } \\
\text { schools }\end{array}$ & 315 & 804 & 41.2 & 58.1 \\
\hline \multicolumn{5}{|c|}{ ThabaNchu } \\
\hline School & $\begin{array}{c}\text { Progressed } \\
2014\end{array}$ & $\begin{array}{c}\text { Progressed } \\
2015\end{array}$ & $\begin{array}{c}\text { \% Progressed } \\
2014\end{array}$ & $\begin{array}{c}\text { \% Progressed } \\
2015\end{array}$ \\
\hline $\mathrm{T} 1$ & 15 & 46 & 33.3 & 48.9 \\
\hline $\mathrm{T} 2$ & 46 & 150 & 34.7 & 88.8 \\
\hline $\mathrm{T} 3$ & 0 & 23 & 0.0 & 11.9 \\
\hline $\mathrm{T} 4$ & 73 & 89 & 40.8 & 44.7 \\
\hline $\mathrm{T} 5$ & 69 & 31 & 35.3 & 40.8 \\
\hline $\begin{array}{l}\text { ThabaNchu project } \\
\text { schools }\end{array}$ & 203 & 339 & 29.2 & 46.9 \\
\hline TOTAL & 518 & 1045 & 36 & 54.0 \\
\hline
\end{tabular}

\section{Discussion}

\section{Extent of learner progression}

The extent of learner progression amongst the candidates who sat the grade 12 examination in the FS varies greatly between schools, with some schools displaying little to no evidence of progression, and others displaying moderate to high levels of progression. In the Motheo district $35 \%$ of the schools $(\mathrm{n}=$ 79) had no progressed learners in 2014 and $28 \%$ had more than the average 
number. In some cases this is due to noncompliance with the progression law in 2013. The percentage of progressed learners increases with a decrease in quintile. In Motheo this ranges from 27,7\% in quintile 1 and 2 schools to $4,2 \%$ in quintile 5 schools. What is not clear from this data is whether high quintile schools implement selection or repetition policies which account for the observed data. By definition, high quintile schools draw learners from higher socio-economic homes. Such learners tend to have enjoyed better educational support at home throughout their lives, and therefore should be expected to be less likely to have the educational backlogs common in poorer communities (Timæus, Simelane, and Letsoalo, 2013). It is also well established that higher quintile schools employ teachers with better content knowledge and pedagogical skill, and perform administrative functions more effectively, than do lower quintile schools (Shalem and Hoadley, 2009; Stott, 2013). It is therefore to be expected that great differences in the need to progress learners exists between schools which serve the SA middle class and those which serve poorer communities.

\section{Effects of learner progression}

It should be noted that the data used here have already been adjusted by the regulatory body, Umalusi. It is likely that this would mainly have applied to upward adjustment of the poorer performing candidates, i.e. the progressed learners. Nevertheless, it is clear from Figure 2 and Table 2 that pass rates for the progressed learners were dramatically lower than pass rates for promoted learners from the same district and from the same school, and that the pass rate depression caused by the presence of the progressed learners was more marked for lower quintile schools. In quintile 1 and 2 schools in Motheo the pass rate of the progressed learners is $31,4 \%,(n=822)$ compared to $73,4 \%(n$ $=109$ ) in the quintile 5 schools. The low pass rate combined with the high percentage of progressed learners had a devastating effect on the overall pass rate in quintile 1 and 2 schools, depressing the pass rate of promoted learners of $82,4 \%$ by 14,4 percentage points to $68 \%$. In quintile 5 schools the depression is only $0,9 \%$, due to the higher pass rate and lower proportion of progressed learners. It appears obvious, therefore, that the decrease in pass rates of the FS province from 2013 to 2014 can largely be attributed to the implementation of the progression law in the FET phase. The pass rate of the promoted learners, alone, would have been $88,7 \%$, which is 1,3 percentage points higher than the $87,4 \%$ of 2013 . 
Few if any of the progressed learners would have sat the grade 12 examination in 2014 had it not been for the introduction of progression law compliance. However, just under half of these learners did pass, with nearly three quarters passing in Thabo Mofutsanyana. Factors which may have contributed to progressed learners managing to pass include: Mark adjustment by Umalusi, which may be devoid of implication to enhanced quality; Extensive focus on the education of grade 12 learners; Grade 11 pass standards being unreliable predictors of grade 12 success.

The difficulties which the teachers and mentors reported are typical of the problems which teachers report regarding social promotion in developed countries (e.g. National Science Teachers Association, 2003) and developing countries (e.g. Haidary, 2013), and correspond to findings from studies performed in other provinces of South Africa (e.g. Lekalakala, 2013). The counterargument which proponents of social promotion generally apply to such reports is that they are based on practical knowledge of the short-term effects of social promotion rather than on rigorous research which includes evaluation of long-term effects. These criticisms are applicable here too. However, the extent of the problem in the low quintile schools we have focussed on is clearly so acute as to make teaching an unpleasant and almost impossibly frustrating and exhausting task. Further, the long-term benefits reported on in the literature have been documented in developed countries, and may not apply to developing countries. Therefore it seems reasonable to question whether the speculated long term benefits could be worth the observed short term costs in the SA context.

It seems reasonable to assume that the progression law would have made schools even more likely to focus on grade 12 learners to the detriment of lower grades than before. It is ironic that this attempt at a short-term solution to the problem of underperformance and progression may very well be contributing to the fact that learners learn poorly in the lower grades, decreasing performance throughout and making progression necessary in order to comply with the progression law. A greater neglect of lower grades, in the name of supporting grade 12 learners, in lower quintile schools relative to higher quintile schools (Clark and Linder, 2006), may contribute to the reason why progression has to occur to such great extents in lower quintile schools, but is virtually unnecessary in high quintile schools. 
Projected effects of learner progression

The high numbers of over-age learners present in grades 10-12 suggests that there are a large number of learners within the FET phase who have repeated previous grades and will shortly be progressed to grade 12 . Therefore, for the next four years we can expect particularly high numbers of progressed learners to reach grade 12 and impact grade 12 pass rates. Three reasons for this are: (1) Some schools only began implementing the progression law in 2015. (2) Since it appears the law was only implemented from 2013 onwards, the 2014 grade $12 \mathrm{~s}$ had probably only been progressed once (i.e. from grade 11 to grade 12). However, from 2015 onwards, grade 12 candidates will include learners who will have been progressed twice or more. (3) Since it appears that progression from grade 9 to grade 10 occurs to a large extent, from 2016 onward we can expect learners to reach grade 12 who have never passed a grade throughout their school careers.

\section{Conclusion}

In summary of the results and discussion given above, we propose the following assertions in response to the research questions of this study:

- $\quad$ Approximately $14,8 \%$ of the candidates $(n=26439)$ who wrote grade 12 in the FS in 2014 had been progressed from grade 11. There is a relationship between quintile and extent of progression, with a range from $4,2 \%$ for quintile 5 schools to $27,7 \%$ for quintile 1 and 2 schools.

- $\quad$ The progressed learners depressed the FS province's 2014 pass rate by 5,9 percentage points. There is a relationship between quintile and extent of pass rate depression by the progressed learners, with a range from a depression of 0,9 percentage points for quintile 5 schools to 14,4 percentage points for quintile 1 and 2 schools.

- $\quad$ The presence of large numbers of unmotivated, ill-disciplined and ill-prepared progressed learners places an immense emotional burden and increased work-load on teachers who are working in the already difficult context of low quintile SA schools. 
- The impact of the progression law, as observed in 2014, can be expected to intensify over the next few years as the proportion of progressed learners, including those progressed multiple times, increases.

\section{Implications, limitations and suggestions for further investigation}

In this paper we have highlighted a dire situation which in all likelihood will worsen with time, particularly over the next few years. Therefore we caution a general refrain from setting unrealistic targets for grade 12 pass rates for the next few years. For example, the FS DBE had announced a $90 \%$ grade 12 pass rate target for 2014 (SABC, 2014). The following reasoning shows that this was an unrealistic target: If it is assumed that $50 \%$ of the progressed learners could pass, the promoted learners would have had to have achieved a $97 \%$ pass rate for the province as a whole to reach the $90 \%$ target. This would have required nearly 10 percentage points increase from the FS's 2013 pass rate, which had placed it the highest performer among the provinces.

The DBE has proposed a number of strategies of dealing with the challenges associated with progression, and has invested much effort and money into remediation programs for the 2015 progressed grade 12 learners. See for example FSDBE (2015) and DBE (2008). We wish to highlight two strategies we consider particularly important:

- Implementation of a campaign to ensure that teachers provide quality teaching and sufficient contact time to lower grades throughout the year. This should help decrease the need for progression since more learners should be able to be promoted on merit.

- $\quad$ Provision and promotion of alternative pathways to the academic stream of the FET phase, in the forms of TVET colleges offering vocational courses, so that it is reasonable for less academically gifted learners to exit school at the end of grade 9 so as to continue their education in a vocational stream. This corresponds to the February 2013 launch of the Decade of the Artisan by the South African minister of Higher Education and Training, Blade Nzimande.

It is true that this study necessarily only reports some of the short-term effects of the progression law in the FET phase, whereas most of the literature-claims 
in favour of social promotion refer to long-term effects. Consequently, this study has the limitation of reporting effects which can be expected to show bias towards the problems associated with social promotion. This study was also necessarily limited in its scope. Qualitative data were only collected from lower quintile township schools. Also, findings for the FS province are not necessarily generalisable to the rest of the country, particularly provinces such as Gauteng and the Western Cape which may have been more successful in promoting pathways alternative to the academic FET stream. The percentage of 2015 grade 12 s who are progressed learners is only $9 \%(n=55893)$ for the Western Cape, opposed to the Free State's 28\% $(n=35496)$. Only 7\% $(\mathrm{n}=294052)$ of grade 11 and 12 learners in Gauteng are progressed learners in 2015. This is according to data available on the DBE website.

Unfortunately comparable statistics are not available for the other provinces.

Further investigation could attempt to bridge the gaps created by the limitations to our study. This could include surveying teachers, and observing practises, particularly regarding teaching quality for, and time spent on teaching, lower grades, and admission and repetition policies which may influence whether progression is necessary or not. As time passes, studies on the long-term effects of the progression law will be possible. Assuming that Umalusi does not adjust future grade 12 results to the extent that our predictions cannot be valid, it will be interesting to observe whether the prediction we have made that grade 12 results should decline over the next few years does occur. We hope that instead of this happening, however, SA is able to provide solutions to the problems created by the progression law.

\section{Acknowledgements}

We gratefully acknowledge the financial support of Old Mutual, Anglo American, Absa and Murray and Roberts. We are also grateful to the FS DBE for the permission to use the quantitative data used here, and to the teachers and mentors who supplied us with the qualitative data. 


\section{References}

Alexander, K.L., Entwisle, D.R. and Dauber, S.L. 2003. On the success of failure: a reassessment of the effects of retention in the primary school grades. Cambridge University Press.

American Federation of Teachers 1997. Passing on failure: district promotion policies and practices. Washington, D.C.: Author.

Belot, M. and Vandenberghe, V. 2014. Evaluating the 'threat'effects of grade repetition: exploiting the 2001 reform by the French-Speaking Community of Belgium. Education Economics, 22(1): pp.73-89.

Branson, N., Hofmeyr, C. and Lam, D. 2014. Progress through school and the determinants of school dropout in South Africa. Development Southern Africa, 31(1): pp.106-126.

Brophy, J. 2006. Grade repetition. Education policy series, 6: pp.420-437.

Chisholm, L. and Wildeman, R. 2013. The politics of testing in South Africa. Journal of Curriculum Studies, 45(1): pp.89-100.

Clark, J. and Linder, C. 2006. Changing teaching, changing times. Rotterdam, Taipei: Sense Publishers.

Cosser, M., Kraak, A. and Winnaar, L. 2011. Further Education and Training (FET) colleges at a glance in 2010. Human Sciences Research Council.

DBE. 2008. Report of the ministerial committee on learner retention in the South African schooling system. Pretoria: Department of Basic Education.

DBE. 2011. National policy pertaining to the programme and promotion requirements of the national curriculum statement grades $R-12$. Pretoria, Cape Town: Department of Basic Education.

DBE. 2012. South African Schools Act (84/1996): Approval of the regulations pertaining to the National Curriculum Statement Grades R-12. Pretoria: Government Gazette. 
DoE. 1998. Admission policy for ordinary public schools. Government Gazette.

DoE. 2004. Revised National Curriculum Statement. Johannesburg: Department of Education.

DoE. 2007a. National Certificate (Vocational): Further Education and Training Colleges. Pretoria: Department of Education.

DoE. 2007b. National policy on assessment and qualifications for schools in the General Education and Training band. Staatskoerant.

FSDBE. 2015. Plan of action for the progressed learners in 2015 and beyond Retrieved 30 May, 2015, from

https://drive.google.com/file/d/0B2DKbfetnAr8ZUpfWThNVXlsVW8/view

Haidary, A. 2013. Controversy over grade repetition: Afghan teachers' view on grade repetition. Masters dissertation, Karlstad University.

Holmes, C.T. and Matthews, K.M. 1984. The effects of nonpromotion on elementary and junior high school pupils: a meta-analysis. Review of Educational Research, 54(2): pp.225-236.

Jimerson, S.R. 2001. Meta-analysis of grade retention research: implications for practice in the 21st century. School Psychology Review, 30(3): pp.420-437.

Jimerson, S.R., Carlson, E., Rotert, M., Egeland, B. and Sroufe, L.A. 1997. A prospective, longitudinal study of the correlates and consequences of early grade retention. Journal of School Psychology, 35(1): pp.3-25.

Lam, D., Ardington, C. and Leibbrandt, M. 2011. Schooling as a lottery: racial differences in school advancement in urban South Africa. Journal of Development Economics, 95(2): pp.121-136.

Lekalakala, M.G. 2013. Outcomes-based assessment: towards progression and promotion in the general education and training band (grades $R(1)-9$ ). North-West University.

Manacorda, M. 2012. The cost of grade retention. Review of Economics and Statistics, 94(2): pp.596-606. 
Motshekga, A. 2015. Speech delivered at the announcement of the 2014 National Senior Certificate (NSC) examinations results by Mrs Angie Motshekga, Minister of Basic Education, Auckland Park.

Retrieved 11 May 2015, from

http://www.gov.za/minister-angie-motshekga-announcement-2014-matric-res $\underline{\text { ults }}$

National Science Teachers Association. 2003. Standards for Science Teacher Preparation. 40. Retrieved from http://www.nsta.org/pdfs/NSTAstandards2003.pdf

Padayachee, S. 2014. National assessment circular no. 8 of 2014: promotion guidelines for school principals and district managers for the senior phase (Grades 7-9). Pretoria: Department of Education.

SABC. 2014. Free State aims to increase matric pass rate. SABC News.

Shalem, Y. and Hoadley, U. 2009. The dual economy of schooling and teacher morale in South Africa. International Studies in Sociology of Education,19(2): pp.119-134.

Smith, M.L. and Shepard, L.A. 1987. What doesn't work: explaining policies of retention in the early grades. Phi Delta Kappan, 69(2): pp.129-134.

Stott, A.E. 2013. South African physical sciences teachers' understanding of force and the relationship to teacher qualification, experience and their school's quintile. African Journal of Research in Mathematics, Science and Technology Education, 17(1-2): pp.173-183.

Timæus, I.M., Simelane, S. and Letsoalo, T. 2013. Poverty, race, and children's progress at school in South Africa. The Journal of Development Studies, 49(2): pp.270-284. 
Angela Stott

Hercules Dreyer

Peet Venter

School Partnership Project

University of the Free State

stottae $@$ ufs.ac.za

dreyerha@ufs.ac.za

venterpa@ufs.ac.za 
